\title{
Influence of An Age on Organometric Parameters of a Heart at the Antipsychotic Cardiomyopathy
}

\author{
Volkov VP* \\ Tver center of judicial examinations, Russia \\ *Corresponding author: Volkov VP, Tver center of judicial examinations, 170008, A Zavidov St, 24 of 6 Tver, Russia. \\ To Cite This Article: Volkov VP. Influence of An Age on Organometric Parameters of a Heart at the Antipsychotic Cardiomyopathy. Am J Biomed \\ Sci \& Res. 2019 - 3(4). AJBSR.MS.ID.000694. DOI: 10.34297/AJBSR.2019.03.000694
}

Received: May 16, 2019 | Published: June 25, 2019

\begin{abstract}
Summary
By a morphometric method of research and calculation of Cohen's coefficient the force of impact of an age factor on pathomorphological changes of heart at the organ level of his organization at development of a neuroleptic cardiomyopathy was determined. It is established that at patients of different age crucial importance plays not an age factor, but side cardiotoxic effect of antipsychotics leading finally to development of the neuroleptic cardiomyopathy.
\end{abstract}

Keywords: Antipsychotics; Cardiotoxicity; Neuroleptic cardiomyopathy; Pathomorphology of heart; Organ level of organization; Morphometry; Influence of age

\section{Introduction}

As a result of active therapy of both the main mental and concomitant somatic pathology, the life expectancy of mental patients, in particular those suffering from schizophrenia, has increased significantly [1,2]. This process is accompanied by a significant increase in the duration of antipsychotic therapy (APT), thereby significantly lengthening the time of damaging cardiotoxic effects of antipsychotics (AP) on the heart, which is fraught with the development of severe life-threatening iatrogenic pathology - neuroleptic cardiomyopathy (NCMP) [3-6]. In parallel, natural ontogenetic involutional processes develop in the heart [7]. How these two factors interact among themselves and how their joint influence is reflected in a morphologic condition of a heart - this question remains open. In the special literature any information on this problem is not found. According to the modern doctrine of morphology as a science, a merely descriptive method of research is not enough for a correct and objective characteristic of pathologic changes being observed; it is strongly necessary to use objective criteria of functional morphology $[8,9]$ and to be guided by the principle of unity of pathology on various research levels; this principle was postulated by G. G. Avtandilov [9] in the past.

Therefore it seems actual to research a morphofunctional condition of heart in patients with NCMP by use of morphometric research methods which meet modern requirements of the evidence-based medicine $[10,11]$ and allow to objectivize the received results and the made conclusions, because final values of the parameters, which are studied, have the quantitative form and can sufficiently easily be analyzed statistically $[8,9]$. The aim of the present study is to eliminate - at least, partially - the existing gap by studying the effect of age on macroscopic changes in the heart (organ level of its organization) in patients with NCMP.

\section{Material and Methods}

Then autopsy protocols of 140 patients with schizophrenia (83 men and 57 women) who died at the age under 35 years and over 55 years were analyzed. The final diagnosis of each deceased was verified at the autopsy. The criteria of an exception were the expressed signs of a metabolic syndrome (the increased body weight, arterial hypertension, a diabetes mellitus), a chronic pulmonary pathology with hypertension in a small circle of blood circulation, a cachexia. The observations were divided into four groups: I and II were respectively 42 young and 39 elderly patients receiving $\mathrm{AP}$, but had no heart disease and died of non-cardiac causes; groups III and IV included 27 young and 32 elderly patients suffering from NCMP. The following parameters were measured on the macroscopic level: heart mss (m), linear dimensions, perimeter of venous valve openings, and thickness of a wall of ventricles. For analysis of the received data we used an original author's method what we had developed for such studies [12]. For this analysis the outer volume of heart without atria (V) was determined and two relative parameters (both in percent) were calculated: 
1. Cv - coefficient of volume, this coefficient shows a part of the total volume of heart (without atria), and this part falls on the volume of cavities of ventricles.

2. $\mathrm{Cl}$ - coefficient of the left ventricle, this coefficient shows the volume size of the left ventricle with respect to the total volume of both ventricles. In addition, two other parameters were calculated which use a gravimetric characteristic of the heart (m): mass-volume ratio (MVR) and index of density of myocardium (IDM).

A growth of MVR is evidence of a hypertrophy of myocardium, and its diminution is an indication for dilatation of cavities of heart ventricles. IDM clearly shows a strongly expressed correlation with such objective parameters of microstructure of cardiac muscle as stromal-parenchymatous ratio and rate of interstitial edema [12], which quantitatively describe a condition of its intercellular matrix.
Mathematical analysis of the obtained quantitative data included the calculation of such an index as the effect's size by J. Cohen $[13,14]$, which in quantitative terms determines the effect of the studied factor on a particular object of study $[13,15]$. It is believed that the inclusion of the Cohen coefficient $\left(d^{\prime} \mathrm{C}\right)$ in the mathematical data processing tool strengthens the rigor of the study and gives more weight to the analysis, conclusions and recommendations [16]. The following gradation of $\mathrm{d}^{\prime} \mathrm{C}$ is accepted: insignificant - less than 0,20; small - 0,20-0,49; average - 0,50-0,79; big - 0,80 and above $[13,15,17]$. Negative $d^{\prime} C$ values indicate the opposite direction of the effect [17]. The obtained quantitative results were processed statistically (computer program "Statistica 6.0") with the level of significance of differences of $95 \%$ and more $(\mathrm{p} \leq 0.05)$. The d'C calculation is performed automatically using a computer calculator [17].

\section{Results and Discussion}

Table 1: Macroscopic parameters of the heart in the study groups.

\begin{tabular}{|c|c|c|c|c|c|c|}
\hline Indicators Group & $\mathbf{m}$ & $\mathbf{V}$ & $\mathbf{K v}$ & $\mathbf{K l}$ & MVR & IDM \\
\hline I & $283 \pm 72-4$ & $127,1 \pm 5,83,4$ & $32,0 \pm 0,53,4$ & $40,0 \pm 0,52,4$ & $2,22 \pm 0,072$ & $4,16 \pm 0,142-4$ \\
\hline II & $312 \pm 61,3,4$ & $134,7 \pm 6,73,4$ & $32,2 \pm 0,53,4$ & $38,5 \pm 0,61,3,4$ & $2,32 \pm 0,061,3,4$ & $4,60 \pm 0,121,3,4$ \\
\hline III & $350 \pm 131,2$ & $160,2 \pm 6,31,2$ & $41,9 \pm 0,71,2$ & $39,7 \pm 0,72,4$ & $2,18 \pm 0,052$ & $6,09 \pm 0,171,2$ \\
\hline IV & $367 \pm 121,2$ & $170,1 \pm 8,11,2$ & $42,3 \pm 0,91,2$ & $40,8 \pm 0,091-3$ & $2,15 \pm 0,072$ & $6,30 \pm 0,161,2$ \\
\hline
\end{tabular}

The comparison of the studied indices in groups I and II (Table 1) identifies the pronounced and statistically significant ontogenetic changes in four of the six parameters. So, with age $\mathrm{m}$ accrues while $\mathrm{V}$ though also increases, but only at the level of a trend. Owing to this fact the level of MVR too, although slightly, but still statistically significant, raises. The value of $\mathrm{Kv}$ practically does not change, which indicates the absence of the age-related expansion of the cardiac ventricles. On the contrary, the ratio of the ventricular volumes changes with age in favor of the right, as in group II Kl goes down considerably and statistically significantly. In old age IDM also increases significantly. This is not surprising, since it is established that this indicator reflects changes in the extracellular matrix of a myocardium, in particular, the degree of myofibrosis [12], which is often observed during the age- related involutive processes occurring in a heart muscle [4]. The calculation of d'C in the compared groups I and II (Table 2) shows that the influence of an age factor on such organometric parameters of the heart as $\mathrm{m}$ and IDM corresponds to an average degree, on $\mathrm{KV}$ - an insignificant one, and on the others - a small one. The data presented in both tables are fully consistent. In the course of a cardiac remodeling in the development of NCMP (group III and IV) there is a leveling effect of the latter on the severity of ontogenetic shifts of the organometric parameters (Table 1). Very weakly expressed the age-related morphological changes of the heart on the pathological background created by the presence of NCMP are statistically significant only in such an indicator as Kl. This reflects some prevalence of an enlargement of the left ventricle compared to the right one [12].

\begin{tabular}{|c|c|c|c|c|c|c|}
\hline \multicolumn{2}{|l|}{ Table 2: Cohen's coefficient (d'C) in the study groups. } \\
\hline Indicators Group & $\mathbf{m}$ & $\mathbf{V}$ & $\mathbf{K v}$ & $\mathbf{K l}$ & MVR & IDM \\
\hline I-II & 0,789 & 0,204 & 0,069 & $-0,452$ & 0,271 & 0,6 \\
\hline I-III & 1,285 & 1,084 & 3,243 & $-0,098$ & $-0,129$ & 2,469 \\
\hline II-IV & 1,096 & 0,837 & 2,589 & 0,804 & $-0,456$ & 2,146 \\
\hline III-IV & 0,265 & 0,261 & 0,095 & 0,453 & $-0,094$ & 0,248 \\
\hline
\end{tabular}

The sizes d'C for all compared indicators in groups III and IV (Table 2) are in limits of borders small and insignificant. In other words, the force of the influence of an age on the macroscopic condition of the heart in patients suffering from NCMP is extremely small, and all the identified changes are caused by the development of this iatrogenic pathology. The results of a comparative analysis of the dynamics of indicators in paired groups I-III and II-IV, that is in persons of the same age respectively without NCMP and in the presence of one, once again convincingly confirm the proposed situation. In both pairs of the compared groups, the development of NCMP leads to a marked remodeling of the heart, which is documented by the statistically significant changes in the vast majority of the studied organometric parameters (Table 1). The power of an influence ("the size of effect") of the development of 
NCMP at any age for the vast majority of the studied quantitative indicators is very high (Table 2). This fact proves the crucial importance of NCMP in cardiac remodeling at the organ level of the organization definitively.

\section{Conclusion}

Thus, the carried-out analysis of the dynamics of macromorphometric parameters of the heart in the aspect of ontogenesis and the development of NCMP shows the absence of any significant influence of an age factor on the state of the studied organ in the presence of NCMP. Generalizing everything told, it is possible to note that at the development of NCMP in patients of different age the crucial importance in the genesis of various pathological changes of the heart at the organ level of its organization has not an age factor, but the side cardiotoxic effect of AP leading eventually to the development of NCMP.

\section{References}

1. Volkov VP (2009) Somatic pathology and causes of death in schizophrenia. Zh Nevrol Psikhiatr Im S S Korsakova 109(5): 14-9.

2. Volkov VP (2013) Natural causes of death of patients with schizophrenia. Psih zdorov'e 12: 52-7.

3. Volkov VP (2013) Clinical characteristic of an antipsychotic cardiomyopathy. In: Volkov VP (red.) Aktual'nye problemy terapevticheskoj kliniki: kollektivnaya nauchnaya monografiya. Novosibirsk: SibAK Publ 94-116.

4. Volkov VP (2018) Cardiotoxicity of neuroleptics: clinical aspects. LAP Lambert Academic Publ, Beau Bassin-Rose Hil, Mauritius.

5. Buckley NA, Sanders P (2000) Cardiovascular adverse effects of antipsychotic drugs. Drug Saf 23(3): 215-228.
6. Mackin P (2008) Cardiac side effects of psychiatric drugs. Hum Psychopharmacol 23(1): 3-14.

7. Volkov VP (2015) The morphology of the myocardium in the aspect of ontogeny: the morphometric study. In: Innovacii v nauke: sb. st. po materialam L mezhdunar. nauch.-prakt. konf. № 10(47). SibAK Publ, Novosibirsk, Russia, 93-100.

8. Avtandilov GG (1990) Medical morphometry: management. Medicine Publ, Moscow, Russia1990.

9. Avtandilov GG (2002) Fundamentals of quantitative pathological anatomy. Medicine Publ, Moscow,.

10. Grinkhalkh T (2004) The basics of evidence based medicine / lane with English. GEOTAR-MED Publ, Moscow, Russia.

11. Klyushin DA, Petunin YuI (2008) Evidential medicine. Application of statistical methods. Dialectics Publ, Moscow, Russia.

12. Volkov VP (2014) New method of an organometry of heart. In: Paraklinicheskie discipliny: novye metody i diagnosticheskie vozmozhnosti: kollektivnaya monografiya / pod red. V.P. Volkova. SiBAK Publ, Novosibirsk, Russia, pp. 78-100.

13. Cohen J, Cohen P, West SG, Leona S Aiken (2003) Applied multiple correlation/regression analysis for the behavioral sciences. Lawrence Erlbaum Ass, Mahwah NJ, USA.

14. Cohen J (1988) Statistical power analysis for the behavioral sciences ( $2^{\text {nd }}$ edn), Lawrence Erlbaum Ass, Hillsdale, NJ, USA.

15. Shmukler AB (2012) Evidence - based research in psychiatry: analysis of practical significance. Psihiat psihofarmakoter 14(5): 4-13.

16. Hall S (2014) How to calculate effect sizes.

17. Lenhard W, Lenhard A (2016) Computation of effect sizes. 